\title{
An unsuspected case of wheat induced asthma
}

\author{
ALAN J WILLIAMS, SUSAN E CHURCH, RONALD FINN
}

\section{From the Royal Liverpool Hospital, Liverpool}

The aetiology of asthma is still unknown, but there are well recognised trigger factors. ${ }^{1}$ The diagnosis of occupational asthma is rewarding; removing the patient from the work environment leads to an improvement in their asthma in most cases. In patients with inhalant asthma from the house dust mite prolonged allergen avoidance has been shown to improve symptoms. The role of food in asthma, however, remains undefined. Patients with immediate and severe asthma symptoms after ingesting a specific food are likely to recognise the problem easily and thus avoid the food in the future. Difficulty arises if the provoked asthma reaction is delayed after ingestion of the food ("late reaction"). In these circumstances the patient is less likely to notice the relationship, especially if the food is ingested every day. The following case history documents this problem in a patient whose asthma was finally recognised to be wheat induced.

\section{Case history}

A 60 year old woman was referred with a six year history of breathlessness (MRC grade 3), chronic wheeze with nocturnal exacerbations, and a non-productive cough. She was a non-smoker and had no history of eczema or seasonal rhinitis. Her treatment consisted of daily inhaled bronchodilators (salbutamol $1200 \mu \mathrm{g} /$ day, beclomethasone dipropionate $500 \mu \mathrm{g}$ /day) by pressurised aerosol. Her inhaler technique was faultless.

Investigations showed air flow limitation with a peak flow (PEF) of $3001 \mathrm{~min}^{-1}$ (69\% of predicted normal), but greater than $15 \%$ reversibility after inhaled salbutamol. A diagnosis of asthma was made. On careful inquiry the patient volunteered that her symptoms may have been aggravated by foods containing wheat, since she had noticed an improvement in her asthma after starting a weight reducing diet.

She was therefore given instruction to exclude wheat products from her diet, and when she was reviewed three months later her PEF had risen to $4001 \mathrm{~min}^{-1}$ and she had of her own volition stopped all treatment.

Three weeks later she was electively admitted to hospital while continuing her wheat free diet. Skinprick tests (prepared by Bencard) for 24 common inhaled or food allergens showed positive (weal at least $3 \mathrm{~mm}$ greater than control) reactions to 14; the maximal weal diameter was $5 \mathrm{~mm}$ for grass pollens, with a $4 \mathrm{~mm}$ weal recorded for the following foods: potato, wheat grain, flour, egg, milk, cheese, chocolate, mixed beans, cod, lobster, nuts, and coffee. The total

Address for reprint requests: Dr R Finn, Royal Liverpool Hospital, Liverpool L7 8XP.

Accepted 29 September 1986 serum IgE concentration was raised at $172 \mathrm{U} / 1$ (normal range up to 100); but radioallergosorbent tests (RAST) for specific IgE for the grass pollen, house dust mite, cat fur, mould, egg white, and wheat gave negative results (RAST score 0 on the $0-4$ scale). When a solid phase enzyme linked immunosorbent assay (ELISA) was used for detecting serum food antibodies (IgG) to gliadin, ovalbumin, and milk, ${ }^{2}$ antibodies to ovalbumin and milk were found in her serum. Serum IgG, IgA, and IgM, concentrations were normal, as was serum complement (C3 and $\mathrm{C} 4)$. During these three weeks at home her mean daily PEF was $3711 \mathrm{~min}^{-1}$ with a diurnal variation of $6 \%$.

On admission to hospital she was put on a "normal" wheat containing diet (150 g wheat/day) for six days. When she started this her peak flow fell linearly to a nadir of 250 $1 \min ^{-1}$ (fig 1). At this time she began wheezing and needed to start treatment with salbutamol. During this period her FEV $_{1}$ fell from $2 \cdot 1$ (predicted 2.2 l) to 1.75 and her forced vital capacity (FVC) fell from $2 \cdot 8$ (predicted 3.05 ) to $2 \cdot 21$. The wheat diet was discontinued and she was started on an oligoallergenic diet of lamb, pears, and water only. After this her peak flow rate steadily rose to baseline levels within four days, when she was then rechallenged with dietary wheat with the same effect (fig 1).

After the PEF had returned to normal she was given separate double blind challenges with $30 \mathrm{~g} /$ day of wheat or potato placebo disguised as a soup. Once again with dietary wheat there was a steady fall in PEF comparable to the results of the open challenge (fig 2 ). A return to baseline

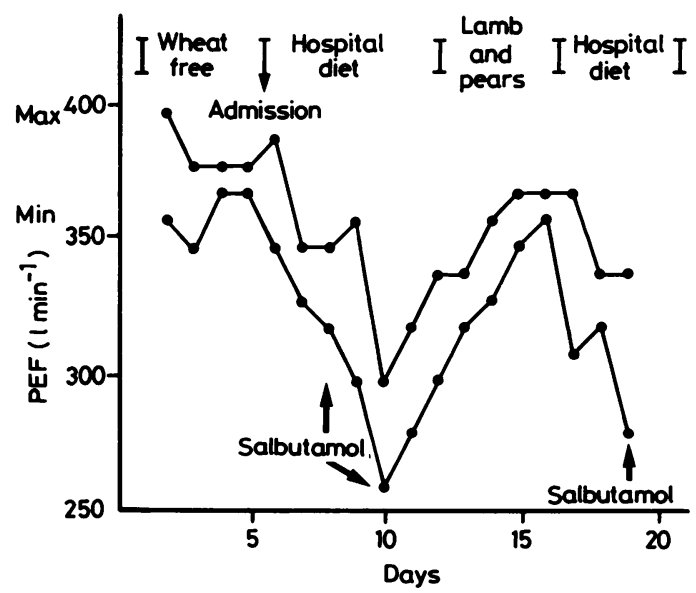

Fig 1 Daily peak flow recordings after the introduction of a normal wheat containing diet and the subsequent response to an exclusion diet. 


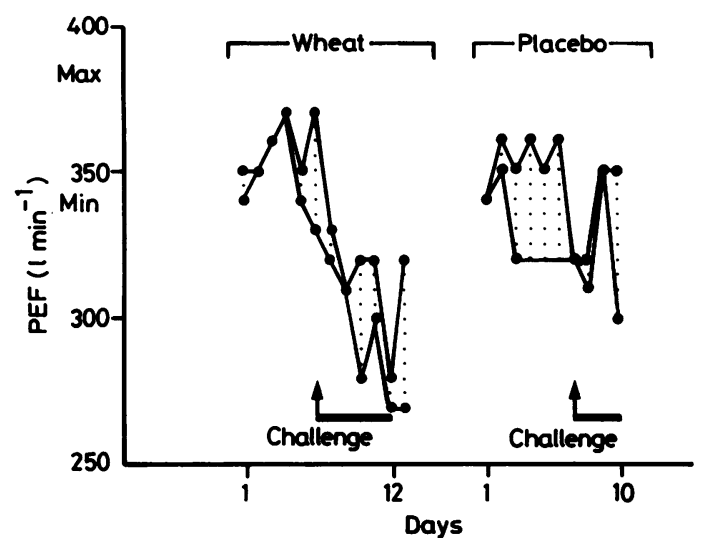

Fig 2 Daily peak flow recordings while the patient was receiving a double blind challenge with wheat and placebo.

peak flow (prechallenge) was attained eight days after cessation of the wheat challenge. During wheat challenge total blood eosinophil count rose from 0.6 to $0.78 \times 10^{9} / 1$, but there was no change in concentration total of any of the serum immunoglobulins or complement. The result of placebo challenge is shown in figure 2 .

\section{Discussion}

Wheat has been known for centuries to induce wheezing in some people with asthma. ${ }^{34}$ Although asthma is probably one of the most prominent symptoms in patients with food intolerance, wheat induced reactions are found infrequently. ${ }^{5}$ For instance, in children clinical wheat sensitivity in asthma has varied in the reported series from $0 \%^{6}$ to $16 \%{ }^{7}$ and seems likely to be of the order of $5 \% .^{8}$

In adults, no figures can be given since there have been no formal prevalence studies. Thus in the general population the frequency of wheat as a cause of asthma is not known, although it is probably relevant in only a small percentage of patients. Nevertheless, for those affected individuals it would be important to make the diagnosis since dietary wheat exclusion, as in this case, may lead to improved qual- $\overrightarrow{\vec{*}}$ ity of life and less dependence on treatment. In our case the only clue to the possibility that wheat was important came from the patient's own observation that improvement had $\frac{\overline{\bar{N}}}{\text {. }}$ occurred during a period of dietary restriction. In past studies skinprick and RAST IgE tests performed to identify specific foods responsible for asthma have proved disap-» pointing ${ }^{5,9}$ In this case a positive skin reaction to wheat was only one of several positive reactions to foods, which were. indistinguishable by weal diameter. The RAST test for $\vec{\overrightarrow{ }}$ specific serum IgE for wheat gave a negative result, as did a test for serum IgG antibodies to gliadin and we cannot therefore support a true "food allergic" or immunological $x$ mechanism. Circulating immune complexes of IgE or IgG $\vec{N}$ with wheat, however, have not been sought and an immunew mechanism still seems possible. ${ }^{10}$

\section{References}

1 Burge P S. Trigger factors in asthma. In: Clark TJH, ed. Steroids in asthma. Auckland: Adis Press, 1983.

2 Barnes RMR, Barton PG, Doig JE, Finn R, Harvey MM,,$\supset$ Johnson PM. Distributions of serum antibodies to wheat $\vec{\theta}$ gliadin and bovine milk in atopic and non-atopic healthyo adults. J Clin Lab Immunol 1983;12:175-8.

3 Floyer Sir J. A treatise on the asthma. 3rd ed. London: Wilkins and Innys, 1726.

4 Salter H Hyde. On asthma. London: Churchill, 1868.

5 Lessof MH, Wraith DG, Merret TG, Merret J, Blisseret PD. $\bar{\partial}$ Food allergy and intolerance in 100 patients-local andô systemic effects. $Q J$ Med 1980;49:259-71.

6 Hill LWH. Food sensitivity in 100 asthmatic children. New Eng $J$ Med 1948;238:657-60.

7 Buffum WP. Asthma in infancy. Rhode Island Medical JournaB 1950;33:461-3.

8 Freedman SS, Sellars W, Providence RI. Food sensitivity: a study of 150 "allergic" children. J Allergy 1959;30:42-9.

9 Aas K. The diagnosis of hypersensitivity to ingested foods. Clin Allergy 1978;8:39-50.

10 Brostoff J, Carin C, Wraith DG, Paganelli T, Levinski RJ: Immune complexes in atopy. Pepys J, Edwards AM, ed. Bath: Pitman Medical, 1979.

\section{Notices}

\section{British Lung Foundation grants}

The British Lung Foundation invites applications for grants of up to $£ 30000$. Grants may cover the cost of personnel or equipment. Application forms can be obtained from the British Lung Foundation, 12a Onslow Gardens, London SW7 3AP. Completed application forms must be submitted by Monday 6 April 1987.

\section{Chicago Lung Conference on Asthma}

The Chicago Lung Association and Chicago Thoracic Society invite submission of papers for the 1987 Chicago Lung Conference on Asthma to be held October 8 and 9
1987. Topics and chairmen are: pharmacology (L) Diamond), late asthmatic response (G Larson), neurohumoral interactions (A Leff), thermally induced asthma 0 ( $\mathrm{R}$ McFadden), pathogenesis of bronchial hyperactivity (CN Murlas), cell to cell interaction in airways (J Nadel), muscle ${ }_{\sigma}^{\omega}$ physiology and protein biochemistry (N Stephens), airway< responses in animal models (A Wanner). The programme will consist of state of the art presentations by the chairmen. $\mathbb{D}$ Each lecture will be followed by 10 minute abstract: presentations with five minute discussions. The conference 0 will emphasise basic and clinical research. The audience is $\overline{0}$ limited to about 150 people. Further details from Dr尺 Christopher Garrard (chairman of program committee), $\overrightarrow{\mathrm{D}}$ Chicago Lung Association, 1440 West Washington Boulevard, Chicago, Illinois 60607-1878, USA. 